\title{
ADSORÇÃO DE FOSFATO E SULFATO EM SOLOS COM CARGAS ELÉTRICAS VARIÁVEIS(1)
}

\author{
J . C. CASAGRANDE ${ }^{(2)}$, L. R. F. ALLEONI(3), \\ O. A. CAMARGO(4) $\&$ M. BORGE $S^{(5)}$
}

\begin{abstract}
RESUMO
As interações dos ânions fosfato e sulfato com os colóides do solo são expressivas, principalmente com óxidos e hidróxidos de ferro e alumínio, cujas cargas elétricas de superfície variam com o pH e com a força iônica do meio. 0 objetivo deste trabal ho foi estudar a adsorção de fosfato e de sulfato em amostras superficiais e subsuperficiais de um Latossolo Vermelho acriférrico (LVwf), um Latossolo Amarelo ácrico (LAw) e um Nitossolo Vermelho eutroférrico (NVef) da região norte do estado de São Paulo, Brasil. A isoterma de Langmuir foi utilizada para obter a adsorção máxima de fosfato e sulfato pelos solos. Para simular a adsorção, utilizou-se o modelo tetraplanar. As adsorções dos ânions foram superiores nas amostras de subsuperfície, cujos teores de matéria orgânica eram menores. As adsorções máxi mas foram menores no LAw, que apresentou as menores concentrações de óxidos de Fe e Al. A adsorção de fosfato diminuiu com a elevação do pH até 5 ou 6; no entanto, em pH acima de 6 a adsorção aumentou. Para o sulfato, a adsorção diminuiu com a elevação do pH em toda a faixa estudada. Os potenciais elétricos superficiais obtidos pelo modelo tetraplanar não foram realísticos, embora ele tenha se mostrado abrangente quanto ao entendimento dos efeitos do pH e das concentrações de fosfato e sulfato em relação às variações dos potenciais, além de ser eficiente na simulação da adsorção dos ânions.
\end{abstract}

Termos de indexação: fosfato, sulfato, adsorção, pH, modelagem, Latossolos.

\footnotetext{
(1) Recebido para publicação em outubro de 2001 e aprovado em outubro de 2002.

(2) Professor Adjunto, Departamento de Recursos Naturais e Proteção Ambiental, Universidade Federal de São Carlos - UFSCar. Caixa Postal 153 CEP 13600-970 Araras (SP). Bolsista do CNPq. E-mail: bighouse@power.ufscar.br

(3) Livre Docente, Departamento de Solos e Nutrição de Plantas, Escola Superior de Agricultura “Luiz Queiroz" - ESALQ/USP. Caixa Postal 9, CEP 13418-970 Piracicaba (SP). Bolsista do CNPq. E-mail: Irfalleo@esalq.usp.br

(4) Pesquisador Científico, Centro de Solos e Recursos Ambientais, Instituto Agronômico - IAC. Caixa Postal 28, CEP 13001-970 Campinas (SP). Bolsista do CNPq. E-mail: o.camargo@sigmabbs.com.br

(5) Mestranda do Programa de Solos e Nutrição de Plantas, ESALQ/USP. Bolsista da FAPESP. E-mail: miborges@base.com.br
} 


\title{
SUMMARY: PHOSPHATE AND SULFATE ADSORPTION ON SOILS WITH VARIABLE ELECTRIC CHARGE
}

\begin{abstract}
Interactions between $\mathrm{P}$ and $\mathrm{S}$ anions and soil colloids are significant, mainly those rich in iron and al uminum oxi des, whose ectric surfacecharges vary according to the pH and ionic strength of thesolution. Theobjectiveof this study was theevaluation of phosphate and sulfate adsorption on surface and subsoil samples of a clayey Anionic Acrudox, a medium-textured Anionic Acrudoxand a clayey R hodic Kandiudalf from thenorthern region of the State of São Paulo, Brazil. Maximum phosphate and sulfate adsorption was determined by the isotherm of Langmuir, and the four layer model used for adsorption simulation. Phosphateand sulfateadsorption weresuperior on thesubsoil, whereorganic matter contents werelower. On LAw samples, which presented lowest iron and al umi num oxi de concentrations, maximum adsorption was smaller. Phosphateadsorption decreased when $\mathrm{pH}$ values were evated up to 5 or 6 , but $\mathrm{pH}$ above 6 provided higher adsorption rates. Sulfate adsorption decreased with $\mathrm{pH}$ elevation. Values obtained for the electric surface potential by thefour layer model werenot realistic, al though themodel was efficient for the simulation of anion adsorption and provides a comprehensive understanding of $\mathrm{pH}$, and phosphateand sulfate concentration effects on surface potential variations.
\end{abstract}

Index terms: phosphate, sulfate, adsorption, $\mathrm{pH}$, model.

\section{INTRODUÇÃO}

Os principais constituintes da fração coloidal do sol o nas regiões tropicais são a matéria orgânica, as argilas do tipo 1:1 e, em especial, os óxidos e hidróxidos de ferro e de alumínio, que apresentam cargas elétricas variáveis com o pH e com a força iônica do meio. Nos sol os altamenteintemperizados, os óxidos são os principais responsáveis pela alta retenção de fosfato e de sulfato (Parfitt, 1978). O efeito do pH na adsorção do fosfato e do sul fato varia com a constituição mi neralógica do sol o e com a faixa de $\mathrm{pH}$ estudada (Haynes, 1982). O pH influiu na proporção dos ânions $\mathrm{H}_{2} \mathrm{PO}_{4}{ }^{-}$e $\mathrm{HPO}_{4}{ }^{2-}$ na sol ução do solo, na quantidade de cargas el étricas negativas e positivas, ou seja, no potencial elétrico na superfície dos colóides com cargas elétricas variáveis, e na formação de polímeros de alumínio com el evada capacidade de retenção de fosfato (Haynes, 1982). Para o sulfato, normalmente, ocorre decréscimo na adsorção com a el evação do pH, dependendo do aumento do número de cargas negativas na superfície dos colóides do solo, como observado por Couto et al. (1979) em solos de cerrado brasileiro.

As isotermas de Freundlich e de Langmuir são equações matemáticas utilizadas para descrever e auxiliar a interpretação da adsorção de íons pelos sol os desde Olsen \& Watanabe (1957). Os model os de compl exação de superfície, por sua vez, são de uso mais recente (Barrow, 1987; Casagrande \& Camargo, 1997). Tais modelos interpretam quimicamente a adsorção, considerando a concentração de sol uto, do pH e da força iônica do meio. O model o tetraplanar simula a adsorção em função do pH, considerando a variação do potencial elétrico dos colóides do solo e da quantidade de íons em solução (Barrow, 1987;
Casagrande \& Camargo, 1997). A aplicação do model o a resultados experimentais érestrita, já que os potenciais el etrostáticos no plano de adsorção dos íons fosfato e sulfato, $\psi_{a}$, não podem ser medidos, uma vez que o model o nấo considera as constantes de equilíbrio entre as espécies adsorvidas e os colóides do solo, que são necessárias para o cálculo do potencial. Portanto, é necessário atribuir valor ao potencial elétrico inicial, o que o torna um parâmetroajustável. Casagrande \& Camargo (1997) estudaram a adsorção de fosfato em sol os ácricos e verificaram que, apesar de os valores determinados para potencial eletrostático na simulação da adsorção não serem realísticos, o modelo foi além de um simples ajuste de curva, na medida em que permitiu interpretar as variações de $\mathrm{pH}$ e de concentração de fosfato na solução de equilíbrio.

O objetivo deste trabalho foi avaliar não só o efeito do pH na adsorção de fosfato e sulfato em solos com cargas elétricas variáveis, mas também a adequação da descrição da adsorção desses ânions pelo model o tetraplanar.

\section{MATE RIAL E MÉTODOS}

Foram estudadas três amostras superficiais $(0,0$ a 0,2 m) etrês subsuperficiais (na maior expressão do horizonte B), de um Latossolo Vermelho acriférrico típico(LVwf) textura argilosa/muito argilosa; um Latossolo Amarelo ácrico típico (LAw) textura argilosa e um Nitossolo Vermelho eutroférrico típico (NVef) textura muito argilosa, col etados em Ribeirão Pretoe Guaíra na regiãonorte do estado de São Paulo, Brasil. As amostras foram 
incubadas por três meses, até pH constante, após a adição de carbonato de cál ci o ou ácido cl orídrico, para obter valores de $\mathrm{pH}$ de 4 a 8.

As análises químicas (Quadro 1) foram realizadas conforme Camargo et al . (1986): o fosfato em solução foi determinado por meio da medida colorimétrica do fosfomol ibdato, formado pela reação entre fosfato e mol ibdato em áci do sulfúrico e reduzido com ácido ascórbico; a matéria orgânica foi oxidada com dicromato de potássio para determi nação do carbono orgânico; o pH foi obtido em solução de $\mathrm{CaCl}_{2}$ $0,01 \mathrm{~mol}^{-1}$ na relação solo: sol ução 1:2,5; os teores deóxidos foram obtidos após ataque sulfúrico; o ferro foi reduzido pel o ditionito e compl exado pel o citrato de sódio; oferro e o alumínio mal cristalizados foram solubilizados em ácido oxálico e seu sal de amônio, e o teor de argila foi obtido pel o método da pipeta. O ponto de efeito salino nulo (PESN) foi determinado por titulação com $\mathrm{H}^{+}$e $\mathrm{OH}^{-}$em três concentrações deKCl (Alleoni \& Camargo, 1994a). A carga elétrica líquida foi estimada a partir do gráfico do PESN (Alleoni \& Camargo, 1994b). A superfície espeáfica foi determinada pel o método de Cihacek \& Bremmer (1979), pela retenção do éter monoetílico do etilenoglicol (EMEG), proposto por Heilman et al. (1965).

A adsorção de fósforo foi avaliada após adição de $\mathrm{KH}_{2} \mathrm{PO}_{4}$ em doses equivalentes a 40,80, 120, 160, 200,240 e $280 \mathrm{mg} \mathrm{dm}^{-3}$ de $\mathrm{P}$, sendo utilizado $\mathrm{CaCl}_{2}$ $0,0025 \mathrm{~mol} \mathrm{~L}^{-1}$ como el etrólito suporte. Amostras com 2,00 g de terra fina seca ao ar, em duplicata, foram agitadas por $24 \mathrm{~h}$ em agitador horizontal com $20 \mathrm{~mL}$ de cada solução. O mesmo foi feito para o sulfato, porém as concentrações foram de 2, 4, 8, 16, 24, 32, 48 e $64 \mathrm{mg} \mathrm{dm}^{-3}$ de S, adicionados na forma de $\mathrm{K}_{2} \mathrm{SO}_{4}$. Após a agitação, foi medido o pH, e as suspensões foram filtradas. As quantidades de fosfato e sulfato adsorvidas foram estimadas após subtração do fosfato e do sulfato determinados no sobrenadante em relação à quantidade inicialmente adicionada. Como o pH aumenta com a adição de doses de fosfato, cada isoterma de adsorção foi corrigida para um valor de $\mathrm{pH}$ igual para todas as doses aplicadas. A extrapolação foi feita para valores inteiros de $\mathrm{pH}$ a partir de gráficos construídos, relacionando adsorçãoe pH para cada doseestudada. Para o sulfato, o ajuste não foi necessário, pois o pH permaneceu constante após sua adição aos sol os.

Os valores de adsorção máxima de fosfato e sulfato utilizados no modelo tetraplanar foram estimados a partir da equação de Langmuir $(x / m=$ $\mathrm{KCb} / 1+\mathrm{KC}$ ), em que $x / m$ é a massa de soluto por unidade de massa do adsorvente, $K$ é a constante relacionada com a energia de ligação solutoadsorvente, Céa concentração de equilíbrio do soluto e béa quantidade máxima de sol uto adsorvida. Para a obtenção de b, foram consideradas as isotermas ao $\mathrm{pH} 4$, nas quais a adsorção dos ânions foi maior.

A superfície neutra do modelo tetraplanar é representada por $\mathrm{OH}-\mathrm{S}-\mathrm{OH}_{2}$, na qual ocorre diminuição do potencial elétrico superficial negativo com o aumento da acidez do solo (eq.1), bem como aumento com a elevação do pH (eq.2) (Bowden et al., 1977):

$$
\begin{gathered}
\left(\mathrm{OH}-\mathrm{S}-\mathrm{OH}_{2}\right)^{0}+\mathrm{H}^{+} \leftrightarrow\left(\mathrm{OH}_{2}-\mathrm{S}-\mathrm{OH}_{2}\right)^{+1} \\
\left(\mathrm{OH}-\mathrm{S}-\mathrm{OH}_{2}\right)^{0}+\mathrm{OH}^{-} \leftrightarrow(\mathrm{OH}-\mathrm{S}-\mathrm{OH})^{-1}+\mathrm{H}_{2} \mathrm{O}(\text { eq. } 1 \text { ) }
\end{gathered}
$$

O model o leva em conta as variações de $\mathrm{pH}$, força iônica, concentração do el emento adsorvido e sua afinidade com os colóides do solo, o que assegura ampla aplicabilidade para sol os e minerais (Barrow, 1987).

A reação entre um íon e a superfície carregada do solo envolve um componente que reflete a afinidade química entre ambos. A atividade do íon i próximo da superfície $\left(a_{i s}\right)$ pode ser relacionada com sua atividade em solução $\left(a_{\mathrm{i}}\right)$ da seguinte forma (Bowden et al., 1977): $a_{i s}=K a_{i} e^{-\psi}{ }_{a} \mathrm{ZiF} / \mathrm{RT}$, em que K é a constante de ligação, a qual é característica do íon e da superfície considerada, $Z_{i}$ é a valência do íon, $\psi_{a}$ é o potencial el etrostático no plano de adsor ção a, $\mathrm{F}$ éa constante de Faraday, $\mathrm{R}$ éa constante dos gases e T a temperatura absoluta. O termo $a_{i}$ pode ser substituído por $\alpha \gamma$ c, sendo $\alpha$ a proporção do íon presente, $\gamma$ o coeficiente de atividade e c é a concentração do íon em solução. A atividade $a_{i s}$ do íon pode ser considerada igual à taxa de sítios ocupados em relação aos sítios disponíveis, ou seja $\theta / 1-\theta$, em que $\theta$ é a proporção de sítios ocupados (Bowden et al., 1977). Assim, tem-se a equação 3:

$$
\theta=\frac{K \alpha \gamma c e^{-\psi} a^{Z i F / R T}}{1+K \alpha \gamma c e^{-\psi}{ }_{a} \text { ZiF/RT }}
$$

O modelo tetraplanar calcula os parâmetros ajustáveis, constante de ligação do íon com a superfície dos colóides, K, e o potencial elétrico superficial do solo, $\psi_{a}$, os quais serão utilizados para simular a adsorção pelas amostras de solos para os valores de $\mathrm{pH}$ e concentrações de fosfato e sulfato adicionadas ao solo. Os valores dos potenciais elétricos de superfície também foram cal culados pela equação de Nernst: $\psi_{\mathrm{N}}=59,1(\mathrm{PESN}-\mathrm{pH})$, para compará-los com os obti dos pel o model o tetraplanar.

\section{RESULTADOS E DISCUSSÃO}

Nos três solos, os teores de carbono da camada superficial foram superiores aos das amostras subsuperficiais (Quadro 1). Os solos ácricos revelaram carga líquida negativa em superfície e positiva em subsuperfície, enquanto o Nitossolo apresentou balanço negativo de cargas em ambas as profundidades. Nos solos ácricos, os valores de PESN foram bem mais elevados em profundidade, graças aos menores teores de matéria orgânica e à 
Quadro 1. Atributos químicos, físicos e mineralógicos dos solos

\begin{tabular}{|c|c|c|c|c|c|c|c|c|c|c|c|c|c|c|c|c|}
\hline Solo & Camada & C & $\begin{array}{c}\mathrm{pH} \\
\mathrm{H}_{2} \mathrm{O}\end{array}$ & $\Delta \mathbf{p H}$ & PESN & $\begin{array}{c}\text { Carga } \\
\text { líquida }\end{array}$ & SE & $\mathbf{K i}$ & $\begin{array}{c}\mathrm{Fe}_{2} \mathrm{O}_{3} \\
\text { a.s. }\end{array}$ & $\begin{array}{c}\mathrm{Fe} \\
\text { livre }\end{array}$ & $\begin{array}{c}\text { Fe } \\
\text { m. crist. }\end{array}$ & $\begin{array}{c}\mathrm{Al}_{2} \mathrm{O}_{3} \\
\text { a.s. }\end{array}$ & Al & Caulinita & Gibbsita & Argila \\
\hline & $\mathrm{m}$ & $\mathrm{g} \mathrm{kg}^{-1}$ & & & & $\mathrm{mmol}_{\mathrm{c}} \mathrm{kg}^{-1}$ & $m^{2} g^{-1}$ & & & & 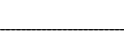 & 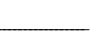 & $\mathrm{g} \mathrm{kg}^{-1}$ & & & - \\
\hline \multirow[t]{2}{*}{ NVef } & $0-0,20$ & 26 & 5,7 & $-0,9$ & 3,7 & -25 & 134 & 1,89 & 270 & 150 & 12 & 170 & 8 & 300 & 120 & 820 \\
\hline & $0,50-0,75$ & 7 & 6,0 & $-0,7$ & 3,6 & -35 & 151 & 1,74 & 280 & 150 & 14 & 200 & 7 & 290 & 150 & 700 \\
\hline \multirow[t]{2}{*}{ LVwf } & $0-0,20$ & 20 & 6,4 & $-0,9$ & 3,6 & -14 & 65 & 0,93 & 320 & 160 & 13 & 200 & 10 & 270 & 460 & 600 \\
\hline & $1,00-120$ & 5 & 5,3 & 0,3 & 5,7 & 2 & 76 & 0,87 & 340 & 170 & 9 & 200 & 7 & 230 & 490 & 640 \\
\hline \multirow[t]{2}{*}{ LAw } & $0-0,20$ & 16 & 4,6 & $-0,6$ & 3,4 & -12 & 65 & 0,98 & 70 & 40 & 2 & 90 & 6 & 240 & 250 & 350 \\
\hline & $1,00-1,30$ & 6 & 5,1 & 0,6 & 6,1 & 6 & 53 & 0,97 & 70 & 40 & 2 & 130 & 8 & 210 & 240 & 450 \\
\hline
\end{tabular}

Latossolo Vermelho acriférrico típico (LVwf), Latossolo Amarelo ácrico típico (LAw) e Nitossolo Vermelho eutroférrico típico (NVef); $\mathrm{C}=$ Carbono; $\Delta \mathrm{pH}=\mathrm{pH}_{\mathrm{KCl}^{-}}-\mathrm{pH}_{\mathrm{H} 2 \mathrm{O}}$; $\mathrm{PESN}=$ Ponto de Efeito Salino Nulo; SE = Superfície específica; $\mathrm{K}_{\mathrm{i}}=$ Í ndice de intemperização $\left(\% \mathrm{SiO}_{2} / 60\right)\left(\% \mathrm{Al}_{2} \mathrm{O}_{3} / 102\right) ; \mathrm{Fe}_{2} \mathrm{O}_{3}$ a.s. e $\mathrm{Al}_{2} \mathrm{O}_{3}$ a.s. = = Óxidos de ferro e alumínio extraídos pelo ácido sulfúrico; m.crist. = mal cristalizado.

predominância de óxidos de ferro e alumínio, mostrando altos valores de PESN (Bell \& Gillman, 1978). O NVef continha teores de caulinita superiores e de gibbsita inferiores aos dos ácricos, o que acarretou valores de PESN inferiores ao $\mathrm{pH}$ do solo, com potencial elétrico negativo em todo o perfil. Os val ores de Ki para oLVwf eLAw foram inferiores a 1,0, o que caracteriza um sistema de carga elétrica variável.

Quanto à granulometria, o NVef apresentou textura muito argilosa, o LVwf argilosa, e o LAw argilo-arenosa. Os valores desuperfícieespecífica (SE) evidenciaram a predominância de minerais deargila 1:1 eóxidos. Os teores deóxidos deferro edealumínio a.s. (extraído pel oácido sulfúrico) foram inferiores no LAw, tanto em superfície como em profundidade.

Para todos os $\mathrm{pH}$, o fosfato e o sulfato foram mais adsorvidos nos horizontes subsuperficiais. Possivelmente, para os sol os ácricos, cujos teores de óxidos eram homogêneos ao longo do perfil, o menor teor de matéria orgânica da camada subsuperficial, com conseqüente PESN mais el evado, proporcionou maior capacidade de adsorção dos ânions. Nestas amostras, o balanço de carga foi positivo até pHs próximos a 5,5. Os valores de $\Delta \mathrm{pH}$ eda carga líquida corroboram essa afirmação. Com isso, a adsorção dos ânions foi maior, em virtude da menor repulsão pelas superfícies dos óxidos de $\mathrm{Fe}$ e de Al, predominantes nessa situação. A ação da matéria orgânica também está associada ao recobrimento dos óxidos e hidróxidos de ferro e de alumínio, bloqueando os sítios de adsorção de sua superfíciee reduzindo sua capacidade de adsorver ânions como o sulfato (Couto et al., 1979). A maior retenção de sulfato em camadas subsuperficiais de solos altamente intemperizados tem importância para o manejo da fertilidade desses solos, uma vez que ela pode reduzir as perdas do ânion por lixiviação.
Independentemente da profundidade e do $\mathrm{pH}, \mathrm{o}$ LAw apresentou valores menores de fosfato adsorvido do que o NVef e o LVwf. As concentrações de $\mathrm{Fe}_{2} \mathrm{O}_{3}$ e $\mathrm{Al}_{2} \mathrm{O}_{3}$ e Fe livre e mal cristalizado nos solos NVef e LVwf foram maiores do que no LAw (Quadro 1), o que explica os menores valores de adsorção máxima para este último (Quadro 2). Os grupos $\mathrm{FeOH}$ e, $\mathrm{Ou}, \mathrm{FeOH}_{2}{ }^{+}$da superfície dos óxidos reagem com o fosfato da solução e for mam complexos do tipo FeOP $\left(\mathrm{O}_{2}\right)$ OFe (Parfitt et al., 1977; Parfitt, 1978). Reações semel hantes ocorrem com caulinita e gibbsita, presentes em grandes quantidades no NVef e no LVwf. Nestes minerais, o fosfato se liga a grupos $\mathrm{Al}(\mathrm{OH})^{2+} \mathrm{H}_{2} \mathrm{O}$ da superfície da gibbsita e das arestas quebradas de caul inita (Parfitt et al., 1977) e forma um complexo do tipo $\operatorname{AIOP}\left(\mathrm{O}_{2}\right) \mathrm{OAI}$, com estrutura semel hante àquela formada na reação com óxidos de ferro.

A adsorção de fosfato diminuiu quando o pH variou de 4 a 5 eaumentou quando passou de 6 para 7, para as doses 160 e $280 \mathrm{mg} \mathrm{dm}^{-3}$ de P (Figura 1), corroborando a constatação de Haynes (1982). Para a menor dose (40 $\left.\mathrm{mg} \mathrm{dm}^{-3}\right)$, todo o fosfato adicionado foi adsorvido pelos sol os. Naidu et al . (1990) eCurtin et al. (1992) também verificaram, em solo argiloso, que o aumento do $\mathrm{pH}$ inicialmente diminuiu a adsorção de fosfato, aumentando apenas a partir de $\mathrm{pH} 5,2$. As curvas de adsorção de fósforo ocorrem dessa forma quando o el etrólito suporte é um sal de cálcio (Camargo et al., 1975; Curtin et al., 1992). Quando o sal contém sódio, a adsorção diminui com a elevação do pH em toda a faixa estudada. Com a el evação do pH, há diminuição da concentração de alumínio em solução e do alumínio trocável e, conseqüentemente, formação de polímeros de Alhidroxila com el evada capacidade de retenção de fosfato (Hayes, 1982). A maior adsorção de fosfato com a elevação do pH pode ser explicada pela 
Quadro 2. Potenciais elétricos calculados pelo modelo tetraplanar $\left(\psi_{\mathrm{a}}\right)$ e pela equação de Nernst $\left(\psi_{\mathrm{N}}\right)$, constantes de dissociação $(\alpha)$, constante de afinidade (K) e adsorção máxima (Mads) para fosfato e sulfato, para diferentes valores de pH para o L Vwf, LAw e NVef, coletados em superfície e profundidade

\begin{tabular}{|c|c|c|c|c|c|c|c|c|c|c|c|c|}
\hline \multirow{2}{*}{ Solo } & \multicolumn{6}{|c|}{ Fosfato } & \multicolumn{6}{|c|}{ Sulfato } \\
\hline & $\mathbf{p H}^{(1)}$ & $\psi \mathrm{a}$ & $\psi_{\mathrm{N}}$ & $\alpha$ & $\mathbf{K}$ & Mads & $\mathrm{pH}^{(2)}$ & $\psi$ a & $\psi_{\mathrm{N}}$ & $\alpha$ & K & Mads \\
\hline & & \multicolumn{2}{|c|}{$-\mathrm{mV}$} & & \multicolumn{2}{|c|}{$\mathrm{L} \mathrm{mol}^{-1} \mathrm{n}$} & & \multicolumn{2}{|c|}{$-\mathrm{mV}-$} & & $\mathrm{L} \mathrm{mol}^{-1}$ & $\mathrm{mg} \mathrm{kg}^{-1}$ \\
\hline LVwf & 5 & -68 & -83 & 0,0088 & 10 & 1.152 & 4,8 & -52 & -71 & 0,99 & 0,01 & 280 \\
\hline \multirow[t]{3}{*}{ Superfície } & 6 & -102 & -142 & 0,081 & 10 & 714 & 6,2 & -60 & -154 & 0,99 & 0,01 & 269 \\
\hline & 7 & -124 & -201 & 0,470 & 10 & 952 & 8,0 & -62 & -260 & 0,99 & 0,01 & 204 \\
\hline & 8 & -125 & -260 & 0,898 & 10 & 1.760 & - & - & - & - & - & - \\
\hline \multirow[t]{4}{*}{ Profundidade } & 4 & -36 & 100 & 0,00087 & 10 & 2.739 & 4,8 & -5 & 53 & 0,99 & 0,001 & 665 \\
\hline & 5 & -67 & 41 & 0,0088 & 10 & 1.867 & 5,4 & -6 & 18 & 0,99 & 0,001 & 359 \\
\hline & 6 & -98 & -18 & 0,081 & 10 & 1.432 & 7,2 & -11 & -89 & 0,99 & 0,001 & 235 \\
\hline & 7 & -120 & -77 & 0,470 & 10 & 1.556 & 8,1 & -15 & -142 & 0,99 & 0,001 & 129 \\
\hline LAw & 4 & -14 & -35 & 0,00087 & 10 & 796 & 3,5 & -19 & -6 & 0,99 & 0,01 & 294 \\
\hline \multirow[t]{3}{*}{ Superfície } & 5 & -58 & -95 & 0,0088 & 10 & 564 & 5,0 & -25 & -95 & 0,99 & 0,01 & 219 \\
\hline & 6 & -90 & -154 & 0,0081 & 10 & 498 & 6,5 & -30 & -183 & 0,99 & 0,01 & 182 \\
\hline & 7 & -102 & -213 & 0,470 & 10 & 723 & 8,0 & -36 & -272 & 0,99 & 0,01 & 180 \\
\hline \multirow[t]{4}{*}{ Profundidade } & 4 & -35 & 121 & 0,00087 & 10 & 1.369 & 3,5 & -13 & 150 & 0,99 & 0,001 & 1.092 \\
\hline & 5 & -73 & 62 & 0,0088 & 10 & 1.398 & 3,9 & -14 & 127 & 0,99 & 0,001 & 936 \\
\hline & 6 & -103 & 3 & 0,0081 & 10 & 620 & 6,4 & -15 & -21 & 0,99 & 0,001 & 655 \\
\hline & 7 & -116 & -56 & 0,470 & 10 & 910 & 8,2 & -20 & -127 & 0,99 & 0,001 & 374 \\
\hline NVef & 4 & -31 & -21 & 0,00087 & 10 & 1.444 & 4,5 & -26 & -50 & 0,99 & 0,01 & 384 \\
\hline \multirow{3}{*}{ Superfície } & 5 & -71 & -80 & 0,0088 & 10 & 646 & 5,6 & -30 & -115 & 0,99 & 0,01 & 229 \\
\hline & 6 & -90 & -139 & 0,0081 & 10 & 1.105 & 7,9 & -39 & -251 & 0,99 & 0,01 & 206 \\
\hline & 7 & -111 & -198 & 0,470 & 10 & 1.395 & 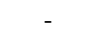 & - & - & - & & - \\
\hline \multirow[t]{4}{*}{ Profundidade } & 4 & -43 & -24 & 0,00087 & 10 & 2.654 & 3,4 & -4 & 12 & 0,99 & 0,001 & 699 \\
\hline & 5 & -74 & -83 & 0,0088 & 10 & 1.975 & 6,2 & -10 & -154 & 0,99 & 0,001 & 252 \\
\hline & 6 & -104 & -142 & 0,0081 & 10 & 1.508 & 8,0 & -23 & -260 & 0,99 & 0,001 & 160 \\
\hline & 7 & -127 & -201 & 0,470 & 10 & 1.481 & - & 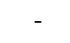 & 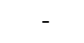 & - & & . \\
\hline
\end{tabular}

(1) Valores de $\mathrm{pH}$ calculados pela variação do pH , considerando a adição de doses de fosfato ao solo. ${ }^{(2)}$ Val ores de pH medidos após a adsorção, pois não houve variação do pH da solução com a adição de doses de sulfato.

formação de complexos Ca-fosfato (Camargo et al., 1975). No entanto, o potencial elétrico dos col óides do solo-Ca torna-se mais negativo com a elevação do pH e, ao mesmo tempo, ocorre aumento na proporção de íons fosfatos divalentes em solução. Por isso, o aumento do número de cargas negativas nos colóides do sol o com a el evação do $\mathrm{pH}$, que provoca a repulsão dos íons fosfatos, é superado pelo aumento da concentração de $\mathrm{HPO}_{4}{ }^{2-}$ em solução (Curtin et al., 1992). Como resultado, há incremento da adsorção com a elevação do $\mathrm{pH}$, a partir de $5\left(\mathrm{NV}_{\mathrm{ef}}\right)$ e $6\left(\mathrm{LV}_{\mathrm{wf}}\right)$ em superfíciee $L A_{w}$ emsuperfícieeprofundidade(Figura 2).

$A$ adsorção de sulfato foi maior nos menores val ores de pH (Figura 3). Como o número de cargas negativas aumentou com o aumento do $\mathrm{pH}$ em solos ácricos, houverepul são do sulfato (Marsh et al ., 1987; Guadalix \& Pardo, 1990). I sto indica que os sítios e, ou, mecanismos de adsorção de sulfato pelos solos não devem ser os mesmos que do fosfato, uma vez que, para este, a adsorção nem sempre dimi nuiu com a el evação do pH. A adsor ção de fosfato pelos col óides do sol o é específica, sendo os oxidróxidos de Fe e Al os principais componentes da fração coloidal responsáveis pela sua adsorção (Parfitt, 1978; Sposito, 1984, 1989; He et al., 1997). Para o sulfato, no entanto, o mecanismo de ligação aos colóides do solo éainda controvertido. Agbenin (1997) verificou quea retenção de sulfato por umAlfissolo caulinítico não foi significativamente afetada pela força iônica e pela natureza do el etrólito suporte $\left(\mathrm{CaCl}_{2}, \mathrm{KCl}\right.$ e $\mathrm{NaCl}$ ), revelando ser a adsorção específica.

Entretanto, outros autores não têm encontrado tal evidência. Para Marsh et al. (1987), é provável que o sulfato seja adsorvido el etrostaticamente, embora a quantidade adsorvida tenha excedido as cargas positivas. O sulfato é adsorvido aos colóides por mecanismo de complexação de esfera externa, graças ao caráter prontamente trocável do sulfato adsorvido (Sposito, 1989). Embora tenham observado esse comportamento, Curtin \& Syers (1990) 
SUPERFÍCIE
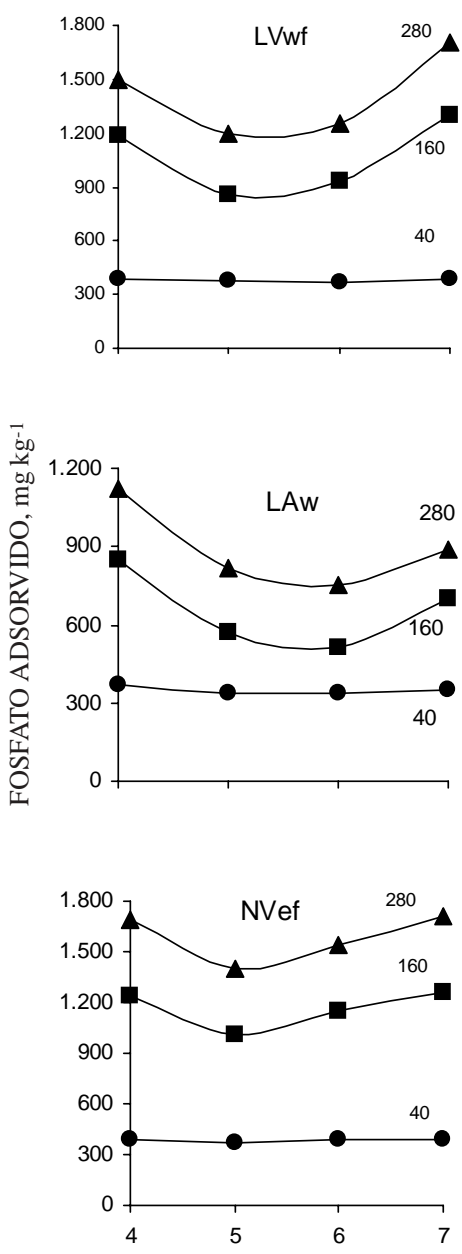

PROFUNDIDADE
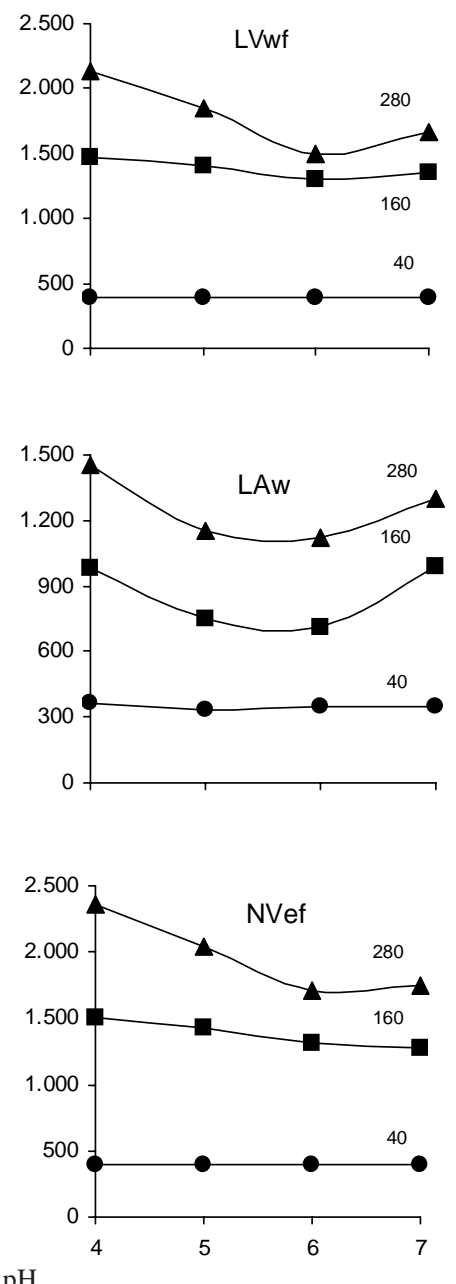

Figura 1. Fosfato adsorvido em função do pH para Latossolo Vermelho acriférrico (LVwf), Latossolo Amarelo ácrico (LAw) e Nitossolo Vermelho eutroférrico (NVef) em superfície e profundidade, para as doses de 40, 160 e $280 \mathrm{mg} \mathrm{kg}^{-1}$ de $P$.

verificaram que a adsorção de sulfato promoveu a formação de cargas positivas pela liberação do $\mathrm{OH}^{-}$. Segundo os autores, o sulfato penetra na camada de Stern, sem, no entanto, coor denar-se quimicamente com os átomos da superfície. De acordo com He et al. (1996), a adsorção de sulfato por caulinita e alumina se dá pela formação de complexo de esfera externa, ocorrendo primeiramente a protonação da superfíciee, a seguir, a adsorção de sulfato. He et al . (1997) verificaram a ocorrência desse tipo de complexo e obtiveram boa adequação da adsorção de sulfato com o model o triplanar.

Os potenciais el etrostáticos $\psi_{a}$ para cada valor de $\mathrm{pH}$ foram estimados para obter o melhor ajuste aos dados experimentais (Quadro 2). Os potenciais elétricos das amostras superficiais foram mais negativos do que das amostras subsuperficiais, considerando o mai or teor de matéria orgânica, uma vez que a constituição mineralógica, para cada solo, foi semelhante nas duas profundidades. Com a el evação do pH, os potenciais el étricos tornaram-se mais negativos, conforme preconizado pel o modelo.

No entanto, para simular a adsorção de sulfato pelo modelo tetraplanar, as diferenças entre os potenciais obtidos pela variação do $\mathrm{pH}$ foram bem menores do que para a de fosfato. Exemplificando, para simular a adsorção de sulfato na amostra superficial do LVwf, o potencial el etrostático variou de -52 para $-62 \mathrm{mV}$, quando o $\mathrm{pH}$ variou de 4,8 para 8,0, respectivamente; para simular a adsorção de fosfato, a variação do potencial elétrico foi de -68 para $-125 \mathrm{mV}$, quando o $\mathrm{pH}$ variou de 5 para 8 , respectivamente, porque o fosfato tem mai or energia de ligação com o sol o que o sulfato. Assim, os val ores de $\psi_{\text {a }}$ obtidos pelo model o tetraplanar para simular a adsorção de fosfato foram de quatro a onze vezes maiores do que para sulfato.

A constante de afinidade (K) para fosfato foi muito superior à do sulfato; ocorrendo o inverso com a constante de dissociação $(\alpha)$, a qual foi bem maior 
SUPERFÍCIE
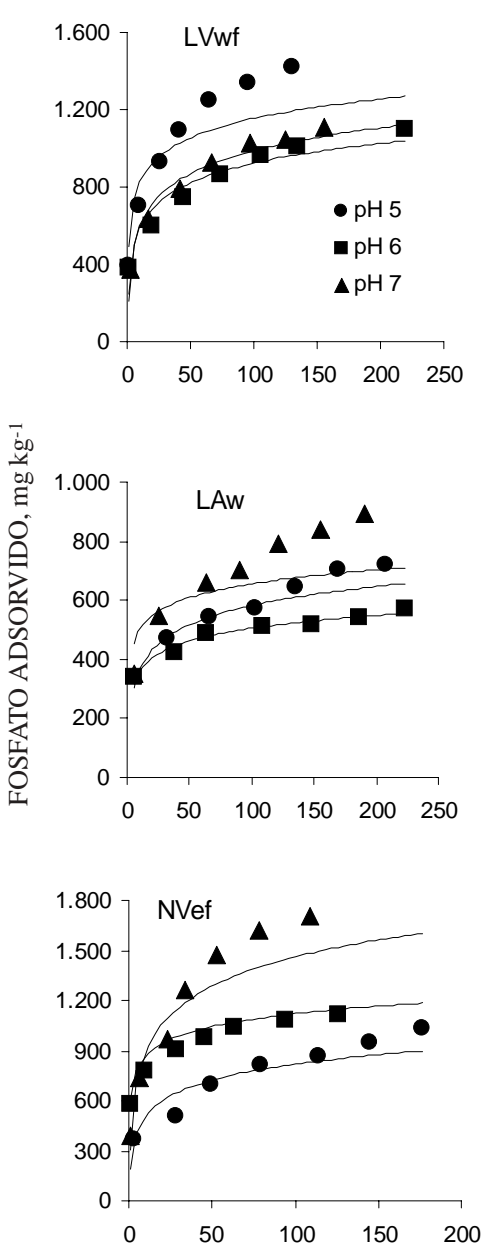

PROFUNDIDADE
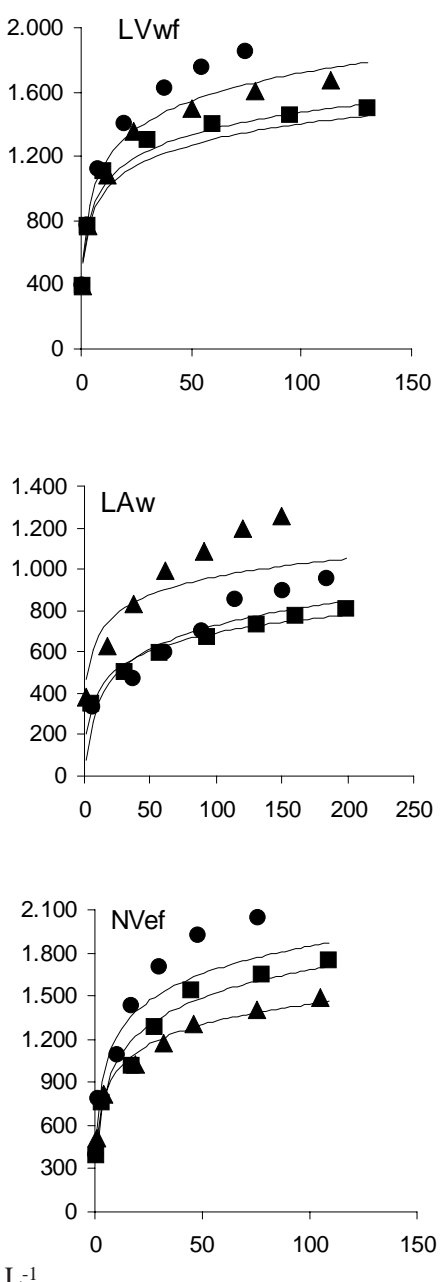

Figura 2. Adsorção de fosfato determinada (marcadores) e simulada pelo modelo tetraplanar (linhas) em função da concentração de equilíbrio (CE ), para diferentes valores de pH para o Latossolo Vermelho ácriférrico (LVwf), Latossolo Amarelo ácrico (LAw) e Nitossolo Vermelho eutroférrico (NVef).

para o sulfato. A adsorção máxima do sulfato foi bastante inferior à do fosfato. Como os parâmetros são multi plicados (equação 3), uma pequena variação de $\psi_{\mathrm{a}}$ com o pH foi suficiente para explicar a adsorção desulfato. Quantoà determinação de $\psi_{N}$ em função do pH (Quadro 2), por meio da equação de Nernst, percebeu-se que os val ores for am substancial mente diferentes e com maior amplitude, quando comparados aos potenciais determinados pelo model otetraplanar. Além disso, ovalor da constante de ligação K, parâmetro ajustável, empregada para a adsorção de fosfato foi de $10 \mathrm{~L} \mathrm{~mol}^{-1}$; para sulfato a constante foi de $0,1 \mathrm{~L} \mathrm{~mol}^{-1}$ para as amostras de superfície, e de 0,01 para as de subsuperfície (Quadro 2). Ou seja, o valor de K foi de cem a mil vezes maior para simular a adsorção de fosfato do que para o sulfato, o que revela maior afinidade do fosfato com os col ói des do sol o, reforçando a hi pótese de ser o sulfato adsorvido principalmente por mecanismos de esfera externa.
Embora estes dois parâmetros, $\psi_{a}$ eK, mostrem a grande diferença quantoà adsorção desses dois ânions, não é possível inferir diretamente a respeito do tipo deligação do sul fato com os colóides dos solos estudados.

O model o tetraplanar pode ser criticado quanto ao real ismo, uma vez que as reações dos íons com as superfícies dos colóides não são especificadas (Barrow, 1984, 1987). Dada a interdependência entre os parâmetros, ocorre ajuste de curva com a variação do potencial el etrostático, com vistas em adequar a simulação dos resultados de adsorção. No entanto, apesar dessa restrição quanto ao ajuste de curva, o modelo representa um avanço em relação às equações de Langmuir e Freundlich, uma vez que simula razoavelmente a variação da adsorção em função do $\mathrm{pH}$. O model otambém éabrangentequanto ao entendimento dos efeitos do pH na adsorção de fosfato e sulfato, considerando as variações dos potenciais el etrostáticos obtidos, e eficiente na simulação da adsorção dos ânions estudados, com 
SUPERFÍCIE
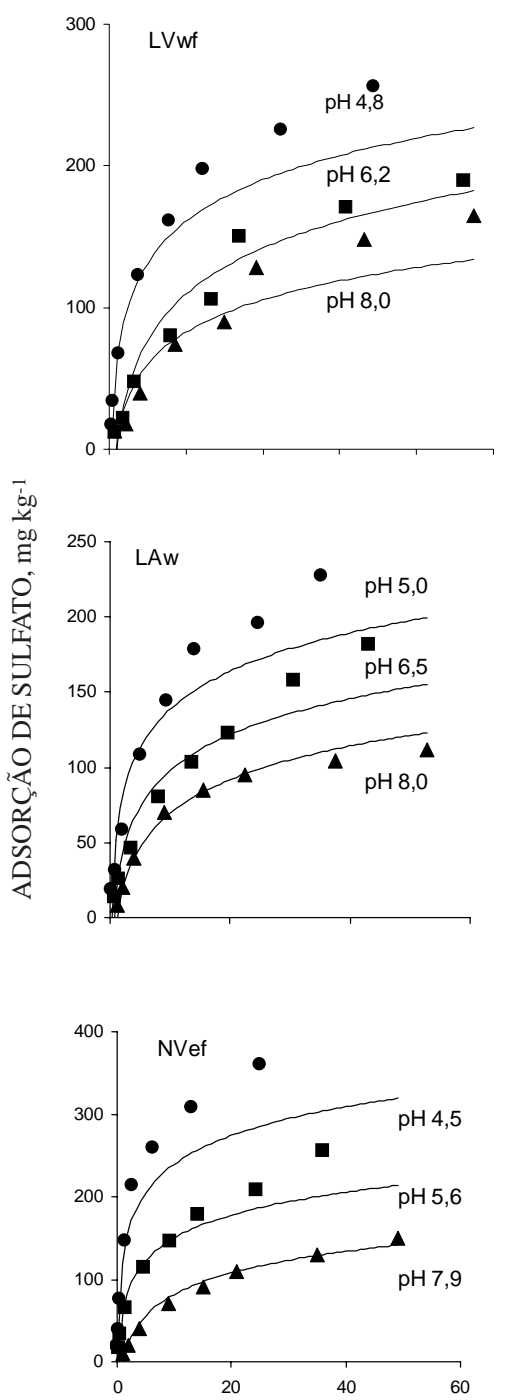

PROFUNDIDADE
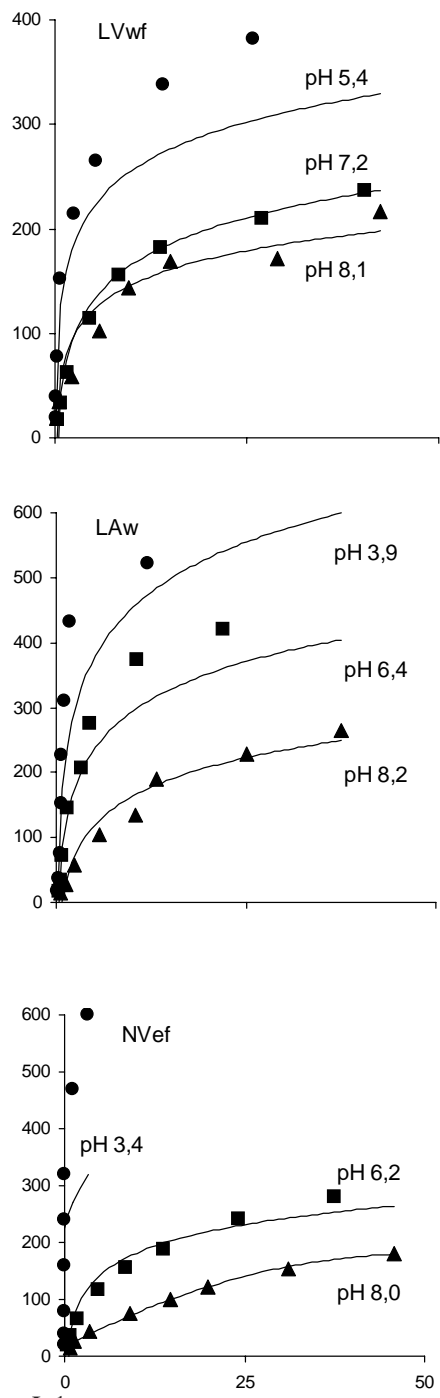

Figura 3. Adsorção de sulfato determinada (marcadores) e si mulada pelo modelo tetraplanar (linhas) em função da concentração de equilíbrio (CE), para diferentes valores de pH para o Latossolo Vermelho ácriférrico (LVwf), Latossolo Amarelo ácrico (LAw) e Nitossolo Vermelho eutroférrico (NVef).

exceção apenas para as concentrações mais elevadas das isotermas obtidas para fosfato nos valores mais baixos de pH (Figura 2) e para as concentrações mais elevadas das isotermas de maior adsorção para o sulfato (Figura 3).

\section{CONCLUSÕES}

1. A adsor ção de sulfato diminuiu com a el evação do $\mathrm{pH}$ para toda a faixa estudada, enquanto para o fosfato a adsorção aumentou acima de $\mathrm{pH} 6$, aproximadamente.

2. Os sítios e, ou, mecanismos de adsorção de sulfato pelos solos não devem ser os mesmos que para fosfato, pois, para este, a adsorção nem sempre diminuiu com a el evação do pH.

3. Os potenciais elétricos superficiais obtidos pelo model o tetraplanar não foram realísticos, embora o modelo tenha sido eficiente na simulação e compreensivo quanto ao entendimento dos efeitos do pH na adsorção de fosfato e sulfato.

\section{LITE RATURA CITADA}

AGBENIN, J.O. Sulfate retention by kaolinitic Alfisols from Nigerian savanna. Soil Sci. Soc. Am. J., 61:53-57, 1997.

ALLEONI, L.R.F. \& CAMARGO, O.A. Pontos de efeito salino nulo delatossolos ácricos. R. Bras. Ci. Solo, 18:175-180, 1994a. 
ALLEONI, L.R.F. \& CAMARGO, O.A. Potencial elétrico superficial e carga elétrica líquida de Latossolos ácricos. R. Bras. Ci. Solo, 18:181-185, 1994b.

BARROW, N.J . Modelling the effects of $\mathrm{pH}$ on phosphate sorption by soils. J. Soil Sci., 35:283-297, 1984.

BARROW, N.J . Reactions with variablecharge soils. Netherlands, Martinus Nijhoff, 1987. 191p.

BELL, L.C. \& GILLMAN, G.P. Surface charges characteristics and soil solution composition in highly weathered soils. In: ANDREW, C.S. \& KAMPRATH, E.J ., eds. Mineral nutrition of legumes in tropical and subtropical soils. Melbourne, CSIRO, 1978. p.37-57.

BOWDEN, J.W.; POSNER, A.M. \& QUIRK, J.P. I Ionic adsorption on variable charge mineral surfaces. Theoretical-charge devel opment and titration curves. Aust. J . Soil Res., 15:12136, 1977.

CAMARGO, O.A.; RAIJ , B. van \& GROHMANN, F. I nfluência de cátions trocáveis e pH na fixação de fósforo em solos. Ci. Cult., 28:678-681, 1975.

CAMARGO, O.A.; MONIZ, A.C.; J ORGE, J .A. \& VALADARES, J.M.S. Métodos de análise química, mineralógica e física de solos. Campinas, Instituto Agronômico, 1986. 94p. (Boletim Técnico, 106)

CASAGRANDE, J.C. \& CAMARGO, O.A. Adsorção de fosfato em solo com caráter ácrico avaliada por um modelo de complexação de superfície. R. Bras. Ci. Solo, 21:353-360, 1997.

CIHACEK, J.L. \& BREMMER, J.M. A simplified ethylene glycol monoethyl ether procedure for assessment of soil surface area. Soil Sci. Soc. Am. J ., 43:821-2, 1979.

COUTO, W.; LATHWELL, D.J . \& BOULDIN, D.R. Sulfate sorption by two Oxisols and one Alfisol of the tropics. Soil Sci., 127:108-116, 1979.

CURTIN, D. \& SYERS, J .K. Mechanism of sulphate adsorption by two tropical soils. J. Soil Sci., 41:295-304, 1990.
CURTIN, D.; SYERS, J.K. \& BOLAN, N.C. Phosphate sorption by soil in relation to exchangeable cation composition and pH. Soil Chem. Miner., 31:137-149, 1992.

GUADALIX, M.E.\& PARDO, M.T. Sulphatesorption by variable charge soils. J. Soil Sci., 42:607-14, 1990.

HAYNES, R.J. Effects of liming on phosphate availability in acid soils: a critical review. Plant Soil, 68:289-308, 1982.

HE, L.M.; ZELAZNY, L.W.; BALIGAR, V.C.; RITCHEY, K.D. \& MARTENS, D.C. Hydroxyl-sulfate exchange stoichiometry on $\gamma-\mathrm{Al}_{2} \mathrm{O}_{3}$ and kaolinite. Soil Sci. Soc. Am. J., 60:442-452, 1996.

HE, L.M.; ZELAZNY, L.W.; BALIGAR, V.C.; RITCHEY, K.D. \& MARTENS, D.C. I onic strength effects on sulfate and phosphate adsorption on $\gamma$-alumina and kaolinite: triplelayer model. Soil Sci. Soc. Am. J., 61:784-793, 1997.

HEILMAN, M.D.; CARTER, D.L. \& GONZALES, C.L. The ethylene glycol monoethyl ether (EGME) technique for determining soil-surface area. Soil Sci., 100:409-13, 1965.

MARSH, K.B.; TILLMAN, R.W. \& SYERS, J.K. Charge relationships of sulfate sorption by soils. Soil Sci. Soc. Am, J., 51:318-23, 1987.

NAIDU, R.; SYERS, J.K.; TILLMAN, R.W. \& KIRKMAN, J.H. Effect of liming and added phosphate on charge characteristics of acid soils. J. Soil Sci., 41:157-164, 1990.

OLSEN, S.R. \& WATANABE, F.S. A method to determine a phosphorus adsorption maximum of soils as measured by the Langmuir isoltherm. Soil Sci. Soc. Am. J ., 21:144-9, 1957.

PARFITT, R.L.; FRASER, A.R.; RUSSEL, J.D. \& FARMER, V.C. Adsorption on hydrous oxides: II. Oxalate, benzoate and phosphate on gibbsite. J. Soil Sci., 28:40-47, 1977.

PARFITT, R.L. Anion adsorption by soils and soil materials. Adv. Agron., 30:1-50, 1978.

SPOSITO, G. The surface chemistry of soils. New York, Oxford University, 1984. 234p.

SPOSITO, G. The Chemistry of Soils. New York, Oxford University, 1989. 277p. 